\title{
Effects of Planting Cyphomandra betacea Seedlings after Mulching with Accumulator Straw on Soil Nutrient Content under Cadmium Stress
}

\author{
Kewen Huang ${ }^{1, a}$, Lijin Lin ${ }^{2, b}$ and Ming'an Liao ${ }^{1, c *}$ \\ ${ }^{1}$ College of Horticulture, Sichuan Agricultural University, Chengdu, Sichuan, China \\ ${ }^{2}$ Institute of Pomology and Olericulture, Sichuan Agricultural University, Chengdu, Sichuan, China \\ a263733029@qq.com, bllj800924@qq.com, Iman@sicau.edu.cn
}

${ }^{*}$ Corresponding author. Kewen Huang and Lijin Lin contributed equally to this work.

\begin{abstract}
Keywords: Cyphomandra betacea; Accumulator straw; Soil nutrient content; Cadmium stress Abstract: A pot experiment was carried out to study effects of planting Cyphomandra betacea seedlings after mulching with four accumulators (Trifolium repens, Eclipta prostrata, Conyza canadensis and Stellaria media) straws on the content of soil nutrients under cadmium stress. The results showed that all accumulator straws could improve the content of soil nutrients in varying degrees. And mulching with $C$. canadensis straw maximized the content of alkaline nitrogen, available phosphorus, available potassium and organic matter in cadmium contaminated soil. Therefore, planting $C$. betacea seedlings after mulching with $C$. canadensis straw in cadmium contaminated soil could effectively increase soil available nutrients content.
\end{abstract}

\section{Introduction}

With the acceleration of urbanization, soil heavy metals are increasing seriously [1]. However, due to the limited ability of soil self-purification, soil ecological environment is easily destroyed when the content of heavy metals is too high [2]. Study has confirmed that high levels of cadmium (Cd) contamination not only inhibited the growth of soil microorganisms but also reduced the activity of soil enzymes, which would significantly reduce the soil fertility [3]. Therefore, it is significant to study how to directly improve soil available nutrients under $\mathrm{Cd}$ stress. It has been found that planting Capsella bursa-pastoris after applying different accumulator straws to Cd-contaminated soil could promote the growth and Cd content of $C$. bursa-pastoris [5]. However, studies on the effects of mulching with accumulator straw on soil nutrients have not yet been reported. Cyphomandra betacea is a perennial evergreen shrub of the genus Solanaceae, which is rich in nutrients, sweet, and has high ornamental and edible value [6]. This study investigated the effects of planting $C$. betacea seedlings after mulching with four accumulators (Trifolium repens [7], Eclipta prostrata [8], Conyza canadensis [9] and Stellaria media [10]) straws on the content of alkaline nitrogen, available phosphorus, available potassium and organic matter in Cd-contaminated soil.

\section{Materials and Methods}

Materials collection. The shoots of four accumulators (T. repens, E. prostrata, $C$. canadensis, $S$. media) and soil were collected from the farmland of Ya'an Campus of Sichuan Agricultural University (not polluted by Cd) in June, 2014. And fixed all plants at $110^{\circ} \mathrm{C}$ for 15 minutes and dried at $80^{\circ} \mathrm{C}$ until they were weighed after washing them with deionized water. Then cut into small pieces of less than $1 \mathrm{~cm}$ by scissors and then stored. The seeds of $C$. betacea were collected from three-years of fruitful $C$. betacea from the Ya'an Campus of Sichuan Agricultural University in October 2013. And the seeds of $C$. betacea were sowed in the sand plate in June 2014.

Experimental Design. The experiment was conducted in farm of Ya'an Campus of Sichuan Agricultural University. In June 2014, the unpolluted soil was air-dried and passed through a 5-mm sieve. $3 \mathrm{~kg}$ air-dried soil was weighed into each plastic pot $(15 \mathrm{~cm}$ high, $18 \mathrm{~cm}$ in diameter), soaking uniformly $\mathrm{CdCl}_{2} \cdot 2.5 \mathrm{H}_{2} \mathrm{O}$ by $10 \mathrm{mg} / \mathrm{kg}$ and balanced for 4 weeks. In July 2014, the straws of four accumulators were separately mulched in Cd-contaminated soil surface. Coverage was $6 \mathrm{~g}$ per pot and the water was kept moist and equilibrated for one week. Then, the same growth $C$. 
betacea with the four real leaves were transplanted into the pots. Two plants were planted in each pot. Five replicates per treatment and all pots were watered each day to keep the soil moisture about $80 \%$. The distance between pots was $15 \mathrm{~cm}$, and the pot position exchanged aperiodically to weaken the impact of the marginal effects. After 40 days, the soil near the roots of $C$. betacea seedlings was collected and naturally air-dried, and then passed over a $1 \mathrm{~mm}$ nylon screen respectively. The measurement of alkaline nitrogen, available phosphorus, available potassium and organic matter content in soil refers to the method of Bao [11].

Statistical Analyses. Statistical analyses were conducted using statistical software of SPSS 17.0. Data were analyzed by one-way ANOVA with least significant difference at $5 \%$ confidence level.

\section{Results and Discussion}

Alkaline nitrogen content in soil. For the content of soil alkaline nitrogen, compared to uncovered, only mulching with $E$. prostrata straw had no significant effects on the content of alkaline nitrogen in Cd-contaminated soil (Figure 1). Mulching with T. repens, C. canadensis and S. media straws significantly increased the alkaline nitrogen content in soil compared with the uncovered $(P<0.05)$.

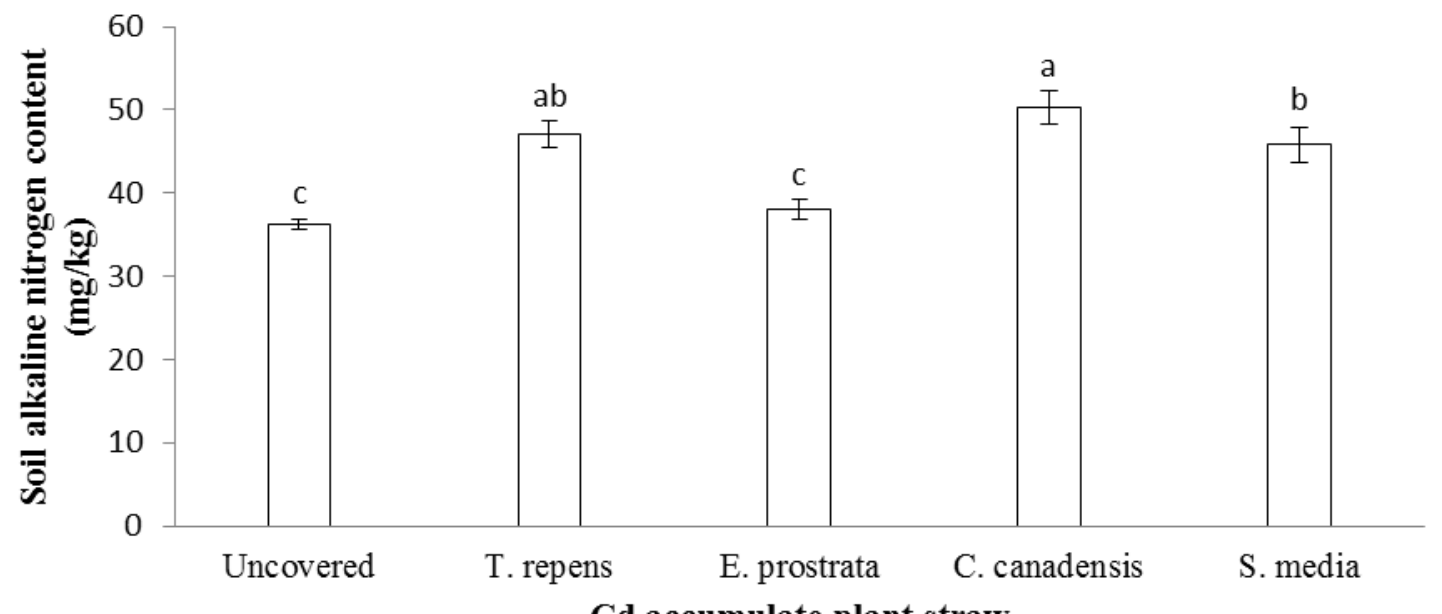

Cd accumulate plant straw

Figure 1 Alkaline nitrogen content in soil

Means with the same letter within each column are not significantly different at $p<0.05$.

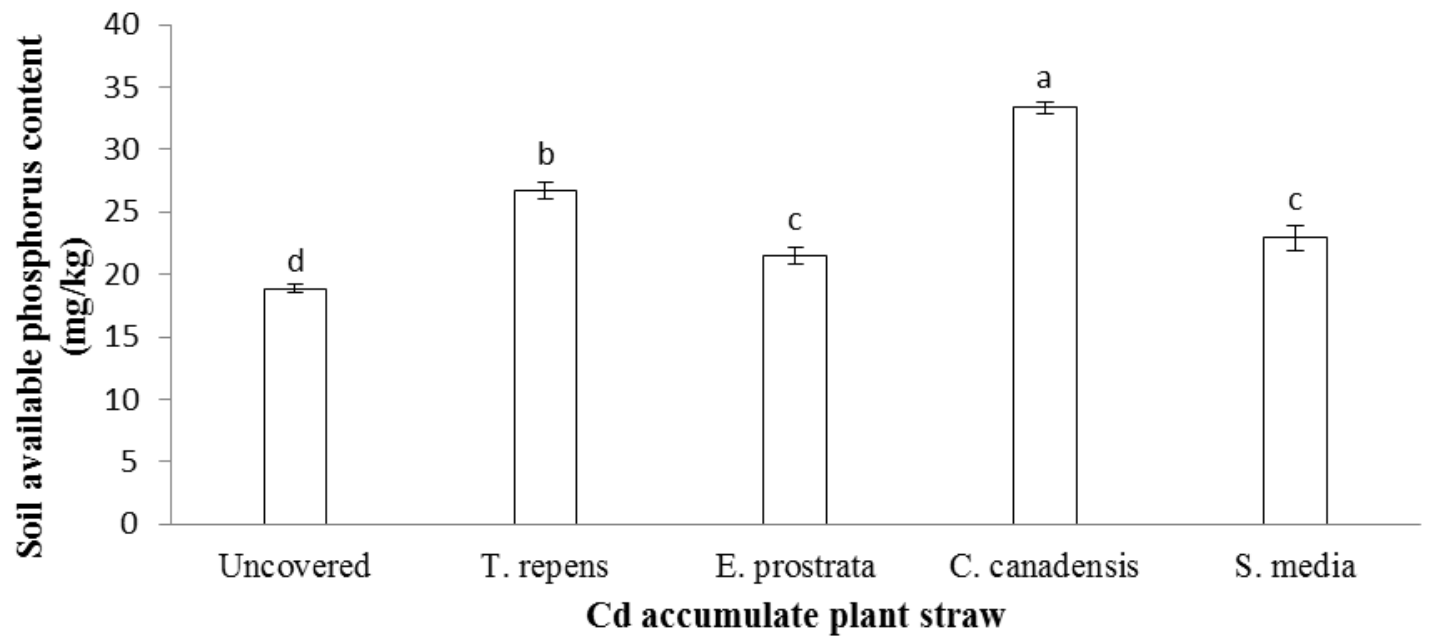

Figure 2 Available phosphorus content in soil

Means with the same letter within each column are not significantly different at $p<0.05$.

Available phosphorus content in soil. For available phosphorus content in soil, compared to uncovered, mulching with accumulators straws could significantly increase the content of available 
phosphorus in Cd-contaminated soil $(P<0.05)$. And the order of soil available phosphorus content from large to small was ranked: $C$. canadensis, $T$. repens, $S$. media, E. prostrata, uncovered (Figure 2).

Available potassium content in soil. Compared to uncovered, mulching with accumulators straws significantly increased the content of available potassium in Cd-contaminated soil $(P<0.05)$. And the order of soil available potassium content from large to small was ranked: $C$. canadensis, $T$. repens, S. media, E. prostrata, uncovered (Figure 3). Among all treatments, the content of soil available potassium was highest by mulching with $C$. canadensis straw.

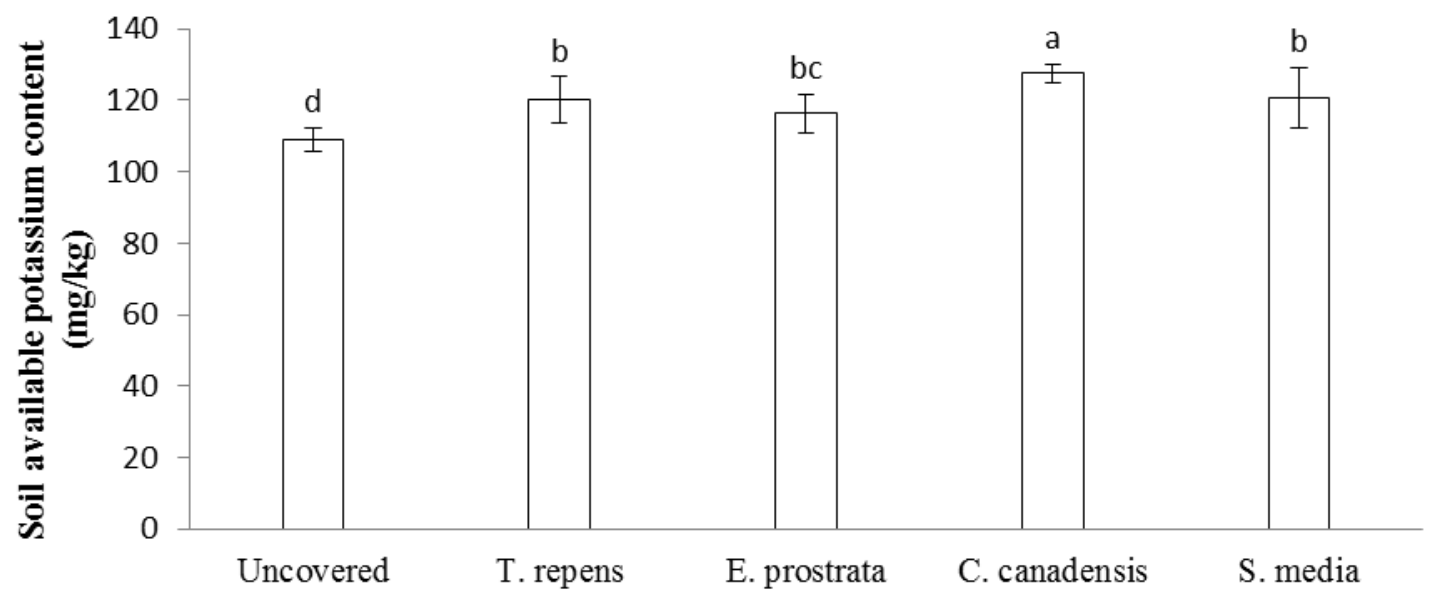

Cd accumulate plant straw

Figure 3 Available potassium content in soil

Means with the same letter within each column are not significantly different at $p<0.05$.

Organic matter content in soil. For the content of soil organic matter, compared to uncovered, only mulching with $E$. prostrata and $S$. media straws had no significant effects on the content of organic matter in Cd-contaminated soil (Figure 4). The order of soil organic matter content from large to small was ranked: C. canadensis, T. repens, E. prostrata, S. media, uncovered (Figure 4).

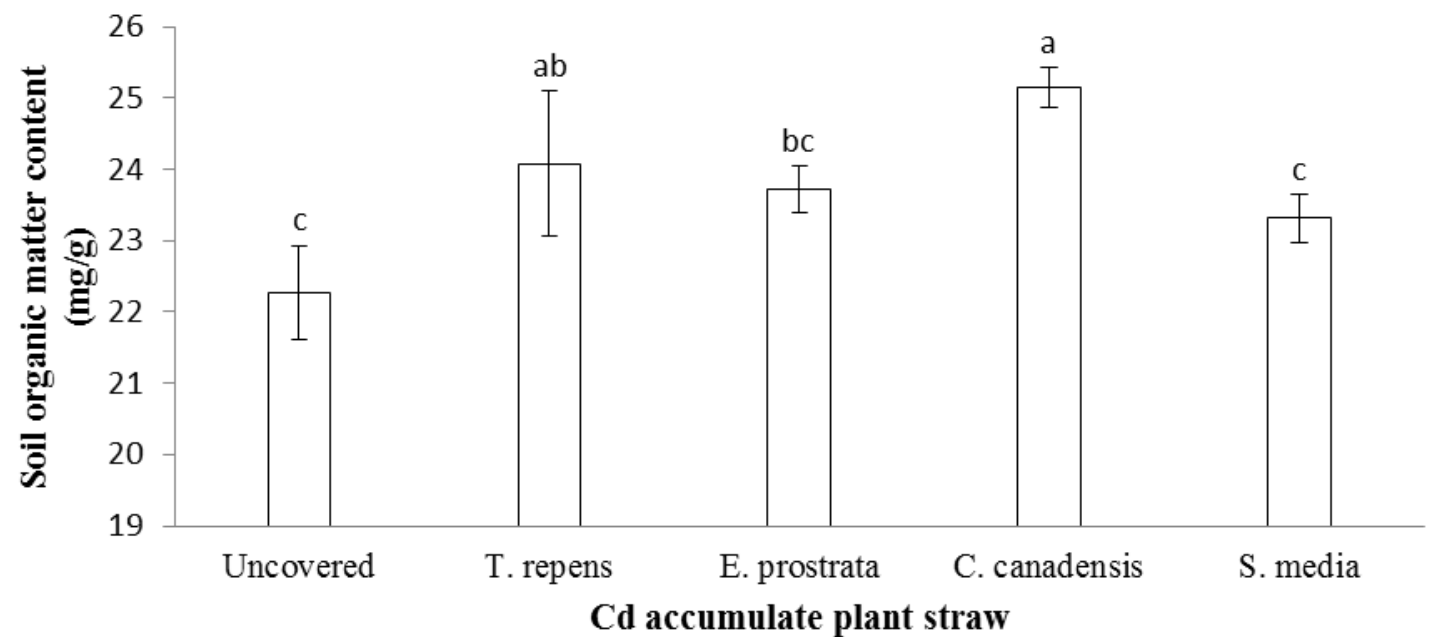

Figure 4 Organic matter content in soil

Means with the same letter within each column are not significantly different at $p<0.05$.

\section{Conclusions}

In cadmium contaminated soil, planting Cyphomandra betacea after mulching with four accumulators (Trifolium repens, Eclipta prostrata, Conyza canadensis and Stellaria media) straws could improve the soil available nutrients content in varying degrees. Compared to uncovered, the content of alkaline nitrogen, available phosphorus, available potassium and organic matter in 
cadmium contaminated soil was significantly higher than other treatments by mulching with $C$. canadensis straw. These results indicated that planting $C$. betacea after mulching with $C$. canadensis could effectively increase the content of available nutrients in soil, which could provide reference for improving the effective nutrients of cadmium contaminated orchard soil.

\section{Acknowledgements}

This work was financially supported by the Application Infrastructure Project of Science and Technology Department of Sichuan Province (2016JY0258).

\section{References}

[1] Y.M. Zeng, K.M. Mao and Y.M. Li: Journal of Yunnan Agricultural University Vol. 20(2005), p. 360.

[2] W.L. Lu and C.Y. Li: Journal of Jilin Institute of Chemical Technology Vol. 27(2010), p. 24.

[3] J.R. Yuan, F.R. Guo, D.S. Zou and Q.R. Zeng: Hunan Agricultural Sciences Vol. 3(2018), p. 114.

[4] Y.M. Wang, D.D. Tang, X.H. Zhang, X.Y. Yuan and L. Xu: Journal of Agro-Environment Science Vol. 36(2017), p. 2445.

[5] L.J. Lin, D.Y. YANG, F.Y. Tang, L. Luo, M.A. Liao and L. Yuan: Chinese Journal of Soil Science Vol. 46(2015), p. 483.

[6] B.G. Yu, L. Qin, F.D. Zhan, Y.Q. Zu, B. Li, J.X. Wang and Y. Li: Journal of Agro-Environment Science Vol. 37(2018), p. 621.

[7] G. Bidar, G. Garçon, C. Pruvot, D. Dewaele, F. Cazier, F. Douay and P. Shirali: Environmental Pollution Vol. 147(2007), p. 546.

[8] L. Luo, L.J. Lin, M.A. Liao, X. Zhang and D.Y. Yang: Acta Agriculturae Boreali-Sinica Vol. 29(2014), p. 216.

[9] S.H. Wei, Q.X. Zhou, U.K. Saha, H. Xiao, Y.H. Hu, L.P. Ren and G. Ping: Journal of Hazardous Materials Vol. 163 (2009), p. 32.

[10]L.J. Lin, B. Ning, M.A. Liao, H.J. Lan and H. Liang: Ecology and Environmental Sciences Vol. 23(2014), p. 673.

[11]S.D. Bao: Agrochemical Soil Analysis (3rd edition, China Agriculture Press, Beijing, China 2000). 